\title{
The electrooxidation of small organic molecules on platinum nanoparticles supported on gold: influence of platinum deposition procedure
}

\author{
F. J. E. Scheijen • G. L. Beltramo • S. Hoeppener • \\ T. H. M. Housmans • M. T. M. Koper
}

Received: 17 August 2006 /Revised: 29 November 2006 / Accepted: 8 February 2007 / Published online: 19 June 2007

(C) Springer-Verlag 2007

\begin{abstract}
The electrocatalytic properties of small platinum nanoparticles were investigated for the oxidation of $\mathrm{CO}$, methanol, and formic acid using voltammetry, chronoamperometry, and surface-enhanced Raman spectroscopy. The particles were generated by galvanostatic deposition of platinum on a polished gold surface from an $\mathrm{H}_{2} \mathrm{PtCl}_{6}$ containing electrolyte and ranged between 10 and $20 \mathrm{~nm}$ in diameter for low platinum surface concentrations, 10 and $120 \mathrm{~nm}$ for medium concentrations, and full Pt monolayers for high concentrations. $\mathrm{CO}$ stripping and bulk $\mathrm{CO}$ oxidation experiments on the particles up to $120 \mathrm{~nm}$ in diameter displayed pronounced structural effects. The $\mathrm{CO}$ oxidation current-time transients show a current decay for
\end{abstract}

Dedicated to Prof. Dr. Teresa Iwasita on the occasion of her 65 th birthday in recognition of her numerous contributions to interfacial electrochemistry.

F. J. E. Scheijen • G. L. Beltramo • T. H. M. Housmans •

M. T. M. Koper

Laboratory of Inorganic Chemistry and Catalysis,

Schuit Institute of Catalysis, Eindhoven University of Technology,

P.O. Box 513, 5600 MB Eindhoven, The Netherlands

S. Hoeppener

Laboratory of Macromolecular Chemistry and Nanoscience,

Eindhoven University of Technology,

5600 MB Eindhoven, The Netherlands

Present address:

G. L. Beltramo

Institut für Bio- und Nanosysyteme 4 (IBN4),

Forschungszentrum Jülich,

52425 Jülich, Germany

Present address:

M. T. M. Koper $(\square)$

Leiden Institute of Chemistry, Leiden University,

P.O. Box 9502, 2300 RA Leiden, The Netherlands

e-mail: M.Koper@chem.leidenuniv.nl low platinum coverages and a current maximum for medium and high coverages. These results were also observed in the literature for particles of 2- to 5 -nm size and agglomerates of these particles. The similarities between the literature and our results, despite large differences in particle size and morphology, suggest that particle structure and morphology are also very important catalytic parameters. Surface-enhanced Raman spectroscopy data obtained for the oxidation of $\mathrm{CO}$ on the Pt-modified $\mathrm{Au}$ electrodes corroborate this conclusion. A difference in the ratio between $\mathrm{CO}$ adsorbed in linear- and bridge-bonded positions on the Pt nanoparticles of different sizes demonstrates the influence of the surface morphology. The oxidation activity of methanol was found to decrease with the particle size, while the formic acid oxidation rate increases. Again, a structural effect is observed for particles of up to ca. $120 \mathrm{~nm}$ in diameter, which is much larger than the particles for which a particle size effect was reported in the literature. The particle shape effect for the methanol oxidation reaction can be explained by a reduction in available "ensemble sites" and a reduction in the mobility of $\mathrm{CO}$ formed by decomposition of methanol. As formic acid does not require $\mathrm{Pt}$ ensemble sites, decreasing the particle size, and thus, the relative number of defects, increases the reaction rate.

\section{Introduction}

Particles of nanoscale diameter are of considerable scientific interest due to their different, often unexpected, catalytic properties compared to bulk electrode materials. Moreover, they are commonly used in technical electrodes. Therefore, understanding of their electrochemical properties is an important issue in the development of efficient fuel 
cell catalysts. Especially the electrocatalysis of small organic molecules, such as carbon monoxide (CO), methanol $(\mathrm{MeOH})$, and formic acid $(\mathrm{HCOOH})$, is an interesting field of study, as these reactions play an important role in fuel cell catalysis $[1,2]$ and they display pronounced sizedependent catalytic properties [3-9]. Due to the fact that platinum is one of the most active dehydrogenation catalysts, Pt nanoparticles are of particular significance.

In a recent paper, Friedrich et al. [9] reported a distinct particle size dependence for the electrooxidation of carbon monoxide on colloidal platinum nanoparticles supported on polycrystalline gold. They found that the $\mathrm{CO}$ oxidation potential on particles with an average diameter of $3 \mathrm{~nm}$ is shifted to higher potentials $(300-500 \mathrm{mV})$ when compared to polycrystalline platinum electrodes. When the diameter of the colloidal particles is increased from $3 \mathrm{~nm}$ to about $10-16 \mathrm{~nm}$, the oxidation potential was found to decrease again. It was suggested that the origin of this "particle size effect" lies in the geometrical structure of the particles (and to a lesser extent in the electronic properties).

Similar effects were observed by Maillard et al. [10-12] for platinum nanoparticles ranging from 1 to $4 \mathrm{~nm}$ supported on glassy carbon (GC). They ascribed the size effect to a limited mobility of $\mathrm{CO}_{\mathrm{ads}}$ on particles smaller than $2 \mathrm{~nm}$. A particle-size-dependent diffusion coefficient was assumed, which is low for small particles $(<2 \mathrm{~nm})$ and higher for larger particles $(>3 \mathrm{~nm}$ ). Although Arenz et al. [13] also obtained similar results for 1- to 5-nm Pt particles supported on carbon, they attributed the difference in $\mathrm{CO}$ oxidation potential for varying particle sizes to the number of defects present on the surface of a particle. As defects are able to dissociate water to form $\mathrm{OH}_{\mathrm{ads}}$ more easily, the higher number of defects on larger particles would result in a shift of the $\mathrm{CO}$ oxidation peak to lower potentials.

For the oxidation of methanol, Park et al. [8] reported a particle size dependence for carbon-supported particles in the range of 2-9 $\mathrm{nm}$. On particles larger than $4 \mathrm{~nm}$ in diameter, the recorded methanol oxidation current densities were found to approach those of polycrystalline Pt electrodes. The decreasing $\mathrm{MeOH}$ oxidation rate for particles smaller than $4 \mathrm{~nm}$ was ascribed to a decrease in contiguous Pt terrace sites. This particle size dependence of the methanol oxidation reaction was also observed by Frelink et al. [6]. However, they measured a more or less constant reaction rate for particles larger than $4.5 \mathrm{~nm}$. Two possible explanations for the decrease in activity with decreasing particle size were given: (1) on smaller particles, the coverage of $\mathrm{OH}_{\text {ads }}$ increases, thus blocking more empty sites, resulting in a decrease in the methanol decomposition rate, or (2) smaller particles have fewer preferential adsorption sites for methanol. In addition to these findings, Cherstiouk et al. [7] observed lower methanol oxidation rates for Pt particles in the range of 1.5-3 nm compared to polycrystalline $\mathrm{Pt}$, which they ascribed to stronger poisoning of the nanoparticles as compared to polycrystalline surfaces due to slower oxidation of CO.

The effect of the particle size in the electrooxidation of formic acid was also investigated by Park et al. [8]. In contrast to methanol, the oxidation rate of formic acid on small particles was found to be considerably higher than on larger particles. It was suggested that formic acid, unlike methanol, does not require Pt ensemble sites to react to $\mathrm{CO}_{2}$, and thus, in combination with a lower poisoning rate, higher oxidation rates are observed. Moreover, unlike the oxidation of $\mathrm{CO}$ and methanol, formic acid does not need an additional oxygen atom (i.e., no reaction with surface oxygen-containing species, like $\mathrm{OH}_{\mathrm{ads}}$, is necessary) to form carbon dioxide [44].

Apart from an interesting particle size effect, the three molecules discussed above are also interesting to study from the perspective of the methanol oxidation scheme (see Fig. 1). Methanol is one of the most promising fuels for a fuel cell, as it can be catalytically oxidized on a platinum surface, yielding $\mathrm{CO}_{2}$ and six electrons per methanol molecule.

$\mathrm{CH}_{3} \mathrm{OH}+\mathrm{H}_{2} \mathrm{O} \rightarrow \mathrm{CO}_{2}+6 \mathrm{H}^{+}+6 \mathrm{e}^{-}$

This reaction has a favorable thermodynamic potential of $0.04 \mathrm{~V}$ vs reversible hydrogen electrode (RHE) and can, theoretically, allow fuel cell power outputs close to that of a hydrogen-based fuel cell. Unfortunately, formation of surface poisoning species and soluble intermediates lowers the overall efficiency of the fuel cell. Carbon monoxide has been identified as the primary poisoning species in many different studies [10, 14-17], while formic acid and formaldehyde are formed as intermediate products [18-21]. It is generally accepted that the oxidation of methanol proceeds through a dual pathway, namely, a direct pathway involving the formation of intermediate species such as formic acid and formaldehyde and an indirect pathway via

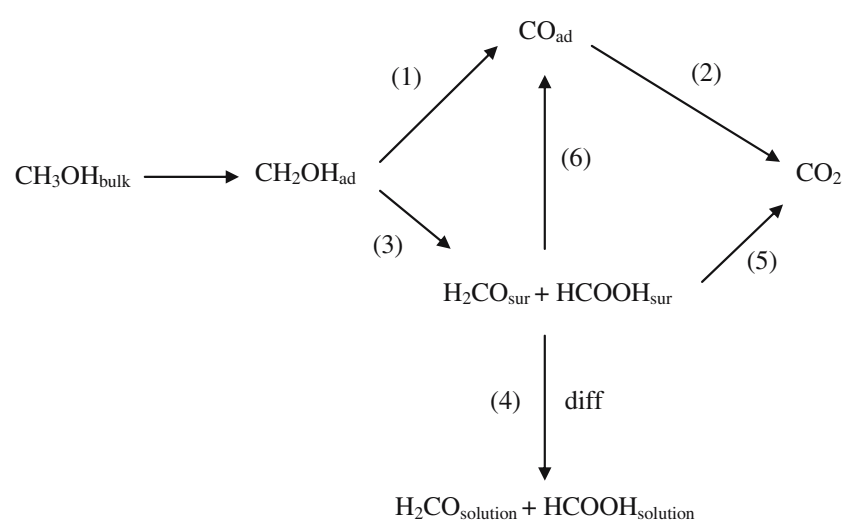

Fig. 1 Schematic representation of the parallel pathway mechanism for methanol oxidation on platinum electrodes as proposed by Baltruschat et al. [19, 20] 
adsorbed CO. Again, the effects of the particle size on the selectivity and activity of the direct and indirect pathways are not known.

Platinum nanoparticles of different sizes can also be obtained by a straightforward electrodeposition procedure, as was also mentioned by Friedrich et al. [9]. The goal of this paper is to study the anomalous catalytic properties of nanoparticles for the oxidation of carbon monoxide, methanol, and formic acid as synthesized using this procedure. As $\mathrm{CO}$ acts as a neutral probe toward the surface reactivity and structure sensitivity, this reaction will be used as a model reaction for studying the particle size effect. The oxidation of methanol and formic acid will be discussed in light of the findings presented for CO. The Pt nanoparticles will be generated by galvanostatic deposition from a platinum-containing solution on a polycrystalline gold support and characterized by cyclic voltammetry and atomic force microscopy (AFM) [9]. The influence of the $\mathrm{Pt}$ deposition procedure, which generates particles of different sizes and morphologies, on the catalytic activity towards the oxidation of $\mathrm{CO}, \mathrm{MeOH}$, and $\mathrm{HCOOH}$ will be investigated using cyclic voltammetry, chronoamperometry, and surface-enhanced Raman spectroscopy (SERS). Strikingly, although the particles are structurally very different from the better-defined particles from previous studies on particle size effects, the results reported here show many similarities with those studies. This emphasizes the general importance of structural effects and particle morphology on (electro)catalysis.

\section{Experimental setup}

All measurements were performed in a standard threeelectrode cell, which was cleaned by boiling in a 1:1 mixture of concentrated sulfuric acid and nitric acid, followed by boiling twice with Milli-Q water (Millipore Milli-Q gradient A10 system, $18.2 \mathrm{M} \Omega \mathrm{cm}, 3 \mathrm{ppb}$ total organic carbon) before each experiment. The counter electrode consisted of a coiled platinum wire, and the reference electrode consisted of a mercury-mercury sulfate electrode $\left(\mathrm{Hg}\left|\mathrm{Hg}_{2} \mathrm{SO}_{4}\right| \mathrm{K}_{2} \mathrm{SO}_{4}\right.$ (sat) connected via a Luggin capillary.

The working electrode was a gold disk of $5 \mathrm{~mm}$ in diameter embedded in a Teflon sheath, which was mechanically polished with alumina (up to $0.3 \mu \mathrm{m}$ ), rinsed and treated ultrasonically in Milli-Q water before use. Before each experiment, the electrode was cleaned by applying 25 potential sweep oxidation and reduction cycles from 0.055 to $1.805 \mathrm{~V}$ vs RHE at a scan rate of $200 \mathrm{mV} \cdot \mathrm{s}^{-1}$.

The blank electrolyte consisted of $0.5 \mathrm{M} \mathrm{H}_{2} \mathrm{SO}_{4}$ and was prepared with concentrated sulfuric acid (Merck, "Suprapur") and Milli-Q water. The methanol- and formic-acidcontaining electrolytes consisted of the blank electrolyte and 0.1-M methanol (Merck, pro analysi) and 0.1-M formic acid (Merck, extra pure), respectively. Argon (Hoekloos, N50) was used to deoxygenate all solutions.

The AFM used for the characterization of the surfaces was a Multimode Nanoscope IIIa from Digital Instruments, California. For the images, a standard $\mathrm{Si}$ tip from Mikromasch (NSC 35, with a typical force constant of $7.5 \mathrm{~N} \mathrm{~m}^{-1}$ ) was used in the tapping mode.

SERS measurements were performed using a DILOR T64000 spectrograph with a holographic grating of $600 \mathrm{~g} \cdot \mathrm{mm}^{-1}$. The slit and pinhole of the system were both set at $100 \mu \mathrm{m}$, and a CCD camera with $1,024 \times 256$ pixels was used as detector. A 633-nm excitation line from a $\mathrm{He}-$ Ne laser was used with a power of $13 \mathrm{~mW}$ on the sample. The microscope objective was an Olympus 50X, which was not immersed in the electrolyte. The laser spot on the electrode surface had a diameter of $\sim 5 \mu \mathrm{m}$. A notch filter was used to filter the SERS signal produced inside the fiber optics before reaching the sample and the excitation line after scattering from the sample. With this configuration, a resolution of $1.5 \mathrm{~cm}^{-1}$ can be obtained.

The electrode in the SERS experiments was roughened by applying a succession of potential sweep oxidation and reduction cycles in $0.1-\mathrm{M} \mathrm{KCl}$ at $500 \mathrm{mV} \cdot \mathrm{s}^{-1}$ from 1.25 to $-0.25 \mathrm{~V}$ vs the $\mathrm{Ag} / \mathrm{AgCl}$ electrode, with waiting times of $1.3 \mathrm{~s}$ at $1.25 \mathrm{~V}$ and $30 \mathrm{~s}$ at $-0.25 \mathrm{~V}$ [22], leading to roughness factor of ca. 20. Pt was deposited after roughening. The electrochemical cell had an optical quartz window parallel to the electrode surface. Measurements were performed at room temperature $\left(22^{\circ} \mathrm{C}\right)$ with a computer-controlled Autolab potentiostat (PGSTAT12). All potentials reported here have been converted to the RHE scale.

\section{Results and discussion}

System cleanliness and surface structure

The system cleanliness and the structure of the gold electrode were checked by measuring a blank cyclic voltammogram $(\mathrm{BCV})$ in $0.5-\mathrm{M} \mathrm{H}_{2} \mathrm{SO}_{4}$ at a scan rate of $20 \mathrm{mV} \cdot \mathrm{s}^{-1}$. A typical voltammogram of the polished electrode is shown in Fig. 2. The BCV displays the characteristically low double layer charging current and typical surface oxidation region, which starts at ca. $1.35 \mathrm{~V}$ vs RHE.

\section{Platinum deposition and AFM imaging}

The platinum nanoparticles were generated by galvanostatic deposition of platinum on the gold substrate from a $0.02-\mathrm{M}$ $\mathrm{H}_{2} \mathrm{PtCl}_{6}$-containing solution. Three surfaces with low, medium, and high platinum concentrations were generated 


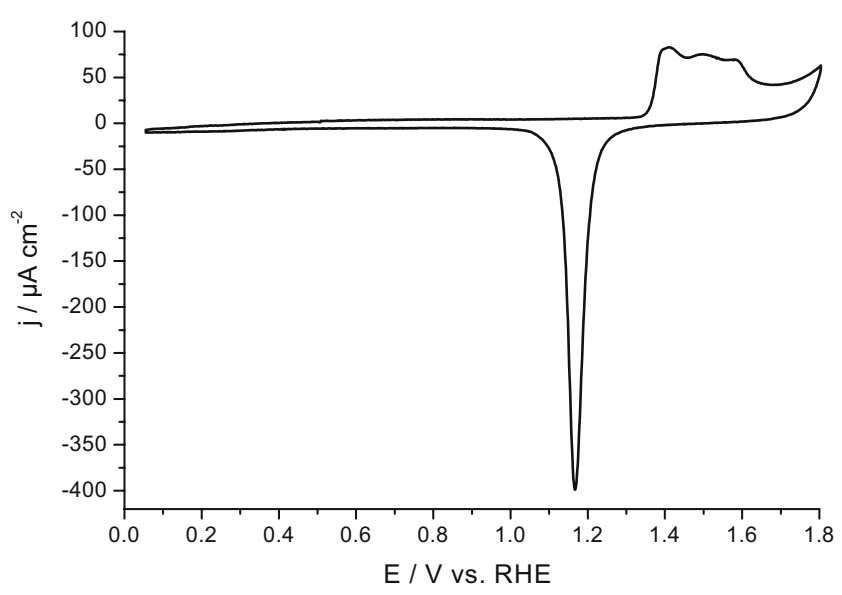

Fig. $2 \mathrm{BCV}$ of polycrystalline gold in $0.5-\mathrm{M} \mathrm{H}_{2} \mathrm{SO}_{4}$ at a scan rate of $20 \mathrm{mV} \cdot \mathrm{s}^{-1}$

by applying a constant current and changing the deposition time. The applied current was $50 \mu \mathrm{A}$, while the deposition times were 5 and $40 \mathrm{~s}$ for the medium and high $\mathrm{Pt}$ coverages, respectively. For deposition times shorter than $5 \mathrm{~s}$, the reproducibility of the results decreases. Therefore, the surface with the lowest platinum concentration was generated by applying a current of $5 \mu \mathrm{A}$ for $5 \mathrm{~s}$.

The generated surfaces were characterized by cyclic voltammetry and AFM imaging. The corresponding BCVs and AFM images are presented in Figs. 3 and 4, respectively. Figure 3 shows that increasing the amount of platinum by increasing the deposition time results in an increase in the charge in the low potential region (between 0.05 and $0.3 \mathrm{~V}$ vs RHE), which can be ascribed to hydrogen adsorption and desorption on the generated platinum particles. The feature starting at $0.85 \mathrm{~V}$ in the positive-going scan can be ascribed to oxidation of the deposited platinum. The corresponding oxide reduction peak is located at $0.67 \mathrm{~V}$ vs RHE in the negative-going scan. Note that for low and medium Pt coverages, the oxide reduction peak seems to consist of two strongly overlapping peaks, suggesting that roughly two different kinds of Pt particles/structures/ agglomerates were electrodeposited. Oxidation and reduction of the gold surface occurs at $1.35 \mathrm{~V}$ in the positive-going scan and $1.17 \mathrm{~V}$ in the negative-going scan, respectively. As the platinum concentration is increased, the Pt oxidation/ reduction charge increases, while the gold oxidation/reduction charge decreases due to masking of the substrate surface. Similar results were obtained by Friedrich et al. [9] in $\mathrm{HClO}_{4}$ by depositing colloidal platinum particles on polished gold electrodes. At high platinum concentrations, the shape of the surface oxidation region starts to resemble that of polycrystalline Pt. Deposition of very large quantities of platinum results in CVs similar to those given by Möller and Pistorius [23] for platinum-gold alloys (see the inset in Fig. 3).
The coverage of the gold-supported platinum particles can be calculated by a method introduced by Friedrich et al. [9], which is based on the real surface area of the gold electrode and the area of the Pt particles. The real surface area of the gold electrode, $A_{\mathrm{Au}}^{0}$, is easily determined by measuring the charge of the gold oxide reduction peak in a $\mathrm{BCV}$ recorded from 0.05 to $1.7 \mathrm{~V}$ vs RHE at a scan rate of $20 \mathrm{mV} \cdot \mathrm{s}^{-1}$, which forms a gold oxide layer that should have a charge of ca. $380 \mu \mathrm{C} \cdot \mathrm{cm}^{-2}[24,25]$. The determination of the Pt nanoparticle area is less straightforward, as the geometrical structure and the size dispersion of the particles are unknown. However, if the electrochemically active area (ECA) of the Pt particles is known, a quantity analogous to the coverage, $\Gamma_{\mathrm{Pt}}$, can be calculated using the real surface area of the gold electrode.

$\Gamma_{\mathrm{Pt}}=\frac{A_{\mathrm{Pt}}}{A_{\mathrm{Au}}^{0}}$

An estimate of the ECA of the platinum particles can be determined from the $\mathrm{Pt}$ oxide reduction charge obtained from the BCVs of the Pt-modified Au electrodes (recorded under the same conditions as suggested by AngersteinKozlowska et al. [24, 25]) and relating this value to the corresponding value of $440 \mu \mathrm{C} \cdot \mathrm{cm}^{-2}$ found for polycrystalline Pt [26]. The calculated coverages for the surfaces with "low," "medium," and "high" platinum concentrations are $0.28,0.36$, and 0.49 , respectively.

As the AFM equipment requires relatively flat and smooth surfaces, the characterization of the nanoparticles was performed using glass-supported gold plates supplied by Arrandee ${ }^{\mathrm{TM}}$ as substrate in the platinum deposition experiment. Before the platinum deposition experiment, the gold plate was flame-annealed and carefully cooled down

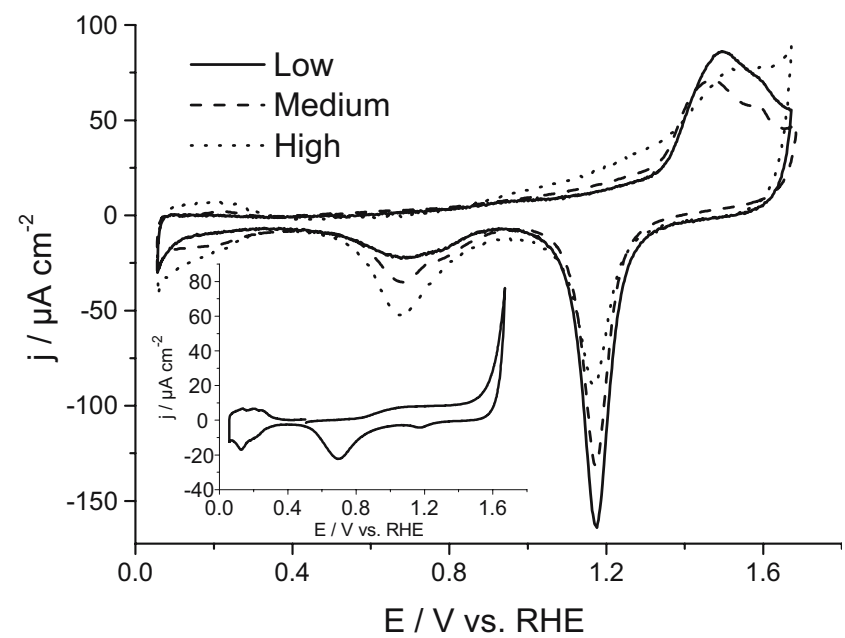

Fig. $3 \mathrm{BCVs}$ of the platinum-modified gold surfaces in $0.5-\mathrm{M} \mathrm{H}_{2} \mathrm{SO}_{4}$ at a scan rate of $20 \mathrm{mV} \cdot \mathrm{s}^{-1}$. The inset shows a $\mathrm{CV}$ of gold with a very high Pt concentration 

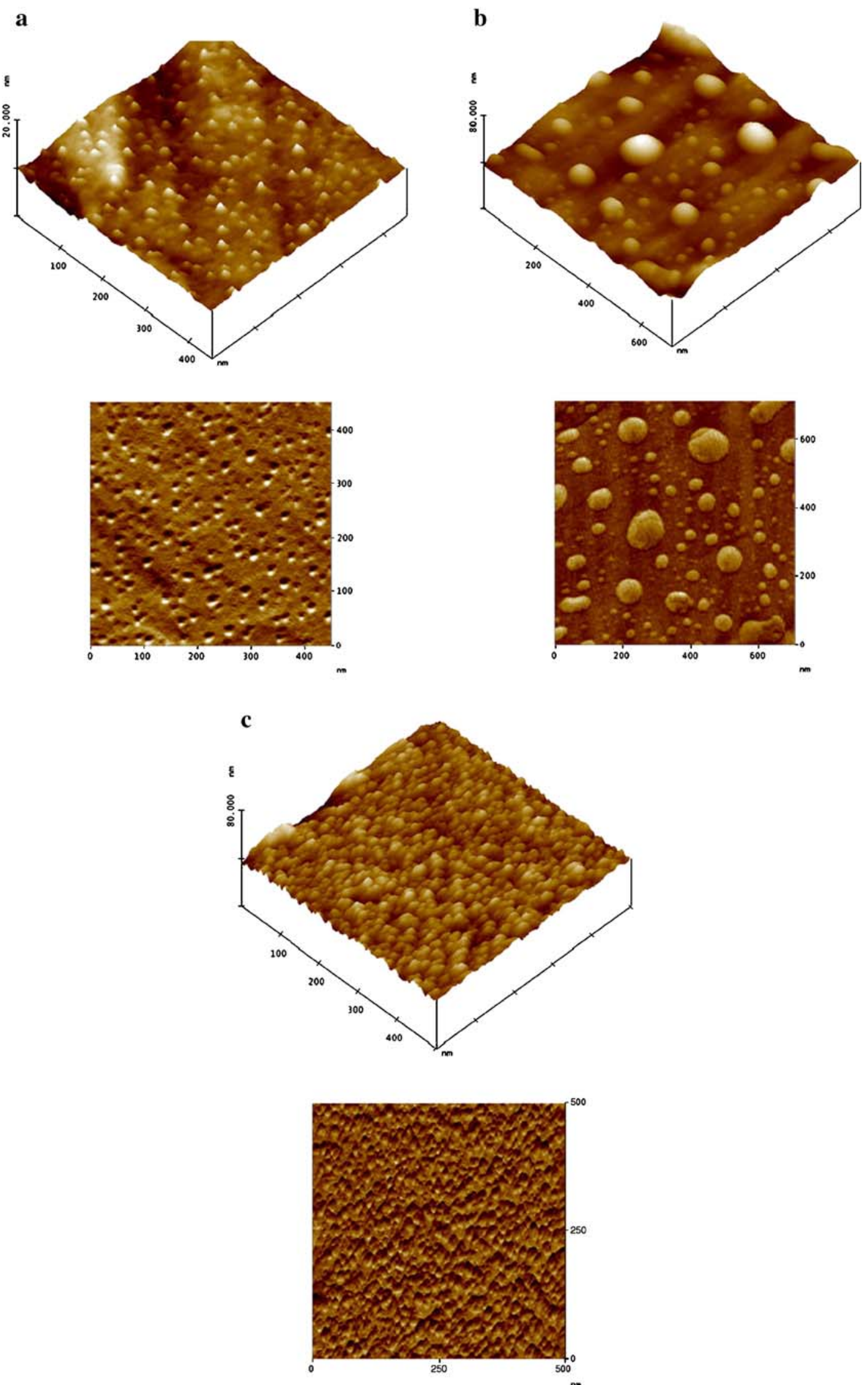

Fig. 4 AFM images of the Pt-Au surfaces with low (a), medium (b), and high platinum concentrations (c) 


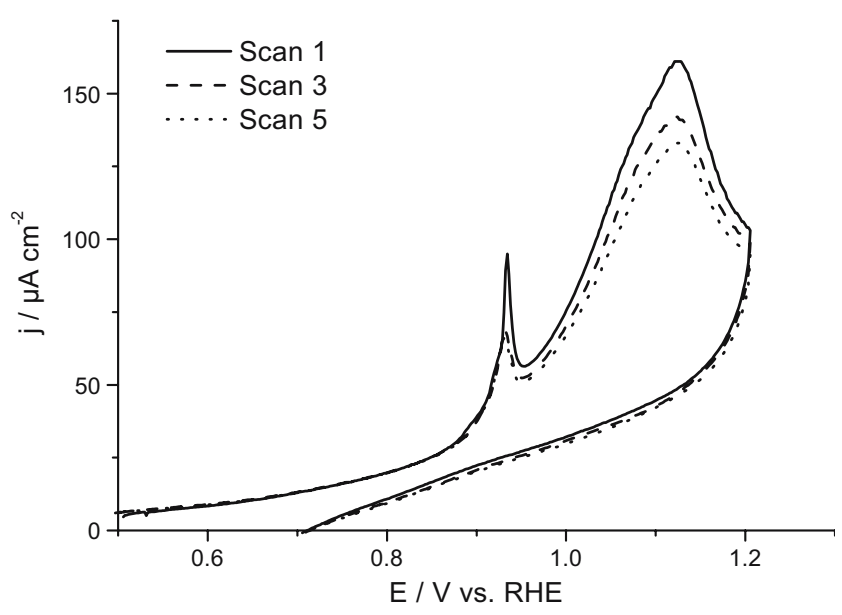

Fig. 5 Influence of repetitive cycling on the $\mathrm{CO}$ electrooxidation characteristics of a $\mathrm{Pt}-\mathrm{Au}$ electrode with a "medium" Pt coverage recorded in a CO-saturated solution of $0.5-\mathrm{M} \mathrm{H}_{2} \mathrm{SO}_{4}$ at a scan rate of $20 \mathrm{mV} \cdot \mathrm{s}^{-1}$

to room temperature in an Argon gas stream. Although this procedure results in large atomically flat $\mathrm{Au}(111)$ planes, it otherwise does not affect the formation of the platinum particles, as is apparent from a comparison of the CVs of the thus generated samples to the CVs shown in Fig. 3.

The resulting AFM images for the low, medium, and high platinum surface concentrations can be found in Fig. 4a-c. Figure 4a shows the surface morphology of the $\mathrm{Pt}-\mathrm{Au}$ electrode with low Pt coverage $\left(\theta_{\mathrm{Pt}}=0.28\right)$ and demonstrates the presence of particles with an average diameter of 10-20 nm. Smaller particles were not identified. At higher platinum surface concentrations (see Fig. 4b,c), the particle size distribution increases to $10-120 \mathrm{~nm}$ for medium Pt loadings and to multilayer-like structures for the high platinum loadings.

Generally, the AFM images clearly show that platinum does not grow epitaxially but rather forms islands on the gold substrate in a Volmer-Weber type growth. For bimetallic systems (in thermodynamic equilibrium), a Volmer-Weber growth mode is expected when the sum of the relative free surface energies (in this case, $\Delta \gamma=\gamma_{\mathrm{Pt}}+\gamma_{\mathrm{Au}-\mathrm{Pt}}-\gamma_{\mathrm{Au}}$ ) of the pure metal $\left(\gamma_{\mathrm{Pt}}\right)$, the pure substrate $\left(\gamma_{\mathrm{Au}}\right)$, and the interface $\left(\gamma_{\mathrm{Au}-\mathrm{Pt}}\right)$ is smaller than zero [27-29].

\section{Carbon monoxide oxidation}

The effect of the different preparation procedures of the gold-supported platinum nanoparticles on the electrooxidation of $\mathrm{CO}$ was investigated by $\mathrm{CO}$ adlayer stripping and bulk $\mathrm{CO}$ oxidation experiments.

\section{Surface stability}

Figure 5 demonstrates the effect of changes in the surface morphology induced by repetitive cycling to high potentials on the continuous oxidation of $\mathrm{CO}$ (i.e., Fig. 5 does not pertain to $\mathrm{CO}$ stripping). Cycling up to $1.2 \mathrm{~V}$ vs RHE results in a decrease in maximum current density for the oxidation of $\mathrm{CO}$, which, in the absence of surface contamination, indicates a decrease in available platinum surface sites. This decrease in available adsorption sites may be due to agglomeration of the platinum particles or embedding/alloying of platinum with the gold substrate [30]. To reduce the influence of morphology changes on our experiments, only a single scan up to $1.2 \mathrm{~V}$ is recorded for each measurement.

Figure 6 illustrates that the platinum deposition rate also influences the morphology of the formed particles, and therefore, affects the electrooxidation reaction. The two surfaces investigated in Fig. 6 were generated by keeping the total deposition charge constant $\left(5,000 \mu \mathrm{C} \cdot \mathrm{cm}^{-2}\right.$ per geometrical surface area) but changing the ratio between the applied current and the deposition time. The surface resulting in the first curve (solid thin line) was generated by a current of $50 \mu \mathrm{A} \cdot \mathrm{cm}^{-2}$ applied for $100 \mathrm{~s}$, while the second surface producing the dashed curve was generated by $500 \mu \mathrm{A} \cdot \mathrm{cm}^{-2}$ for $10 \mathrm{~s}$. The figure clearly shows that increasing the deposition rate results in a decrease in the $\mathrm{CO}$ oxidation potential. Comparing to the results of the groups of Markoviç and Stimming, this suggests that particles generated by slow Pt deposition may be assumed to be smaller in size [9-13].

Interestingly, Arenz et al. [13] proposed that the oxidative stripping of $\mathrm{CO}$ is mainly controlled by the number of defect sites, which may serve as an active center for $\mathrm{OH}$ adsorption, rather than the mobility of $\mathrm{CO}$. Based on the results obtained by transmission electron microscopy, they claimed that decreasing the particle size leads to a concomitant decrease in the number of defects. Moreover, as it is well known that $\mathrm{CO}$ adsorbs and oxidizes

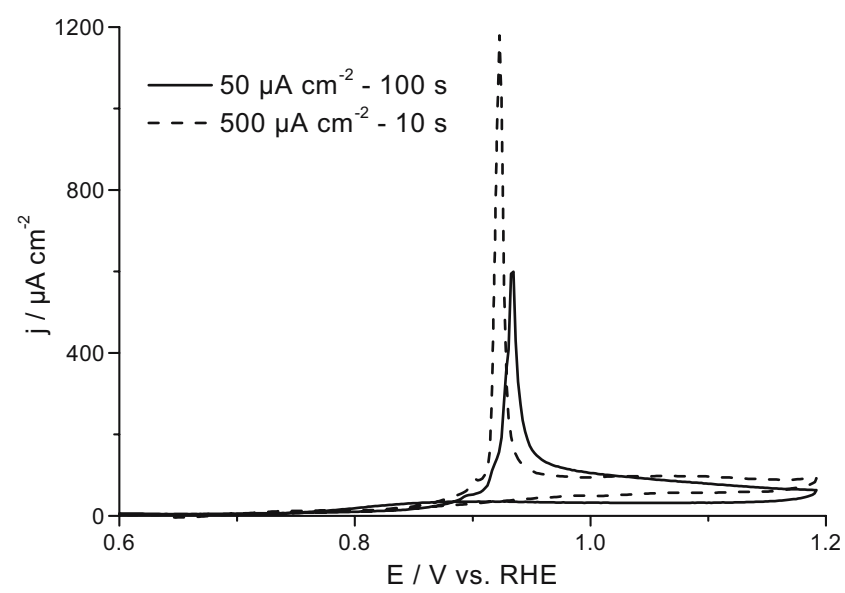

Fig. 6 Influence of the platinum deposition rate on the $\mathrm{CO}$ electrooxidation characteristics of a Pt-modified $\mathrm{Au}$ electrode with a high $\mathrm{Pt}$ coverage recorded in $0.5-\mathrm{M} \mathrm{H}_{2} \mathrm{SO}_{4}$ at a scan rate of $20 \mathrm{mV} \cdot \mathrm{s}^{-1}$ 


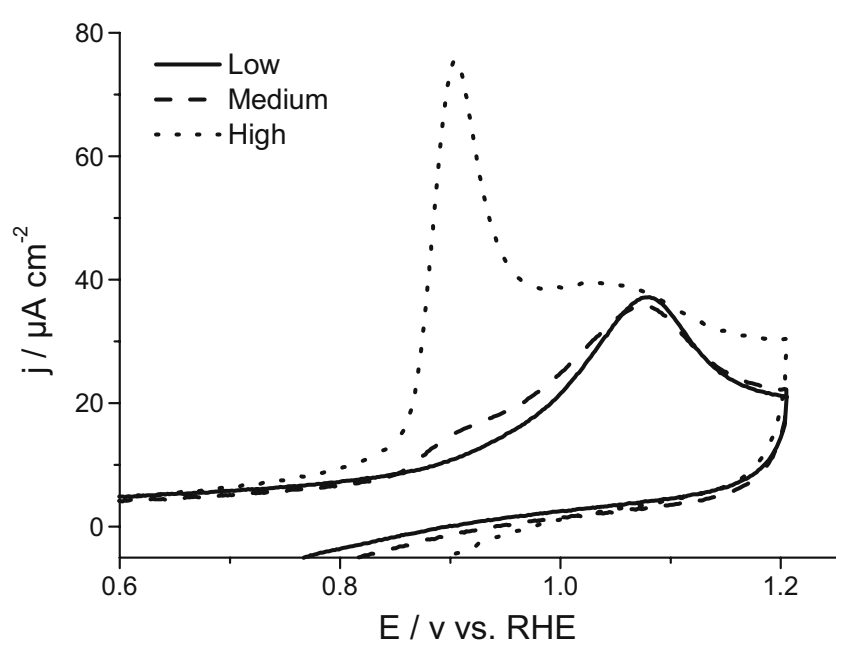

Fig. $7 \mathrm{CO}$ adlayer stripping voltammograms on the Pt-modified $\mathrm{Au}$ electrodes in $0.5-\mathrm{M} \mathrm{H}_{2} \mathrm{SO}_{4}$ at a scan rate of $20 \mathrm{mV} \cdot \mathrm{s}^{-1}$

preferentially at step sites [31-33], the negative potential shift recorded on surface generated by fast platinum deposition may also be ascribed to higher number of surface defects generated under such conditions.

\section{Cyclic voltammetry: saturated $\mathrm{CO}$ adlayer stripping}

Figure 7 displays $\mathrm{CO}$ stripping $\mathrm{CV}$ s recorded on the $\mathrm{Pt}-\mathrm{Au}$ electrodes at a scan rate of $20 \mathrm{mV} \cdot \mathrm{s}^{-1}$. At low platinum coverages, a peak is observed at ca. $1.07 \mathrm{~V}$ vs RHE. This feature remains as the platinum surface concentration is increased. On the Pt-Au electrode with 10- to 120-nm-size particles, another feature appears at $0.9 \mathrm{~V}$ vs RHE, which becomes the dominant feature at high platinum coverages.

As our AFM analysis indicates that the particles on the low coverage $\mathrm{Pt}-\mathrm{Au}$ electrode are ca. $10-20 \mathrm{~nm}$ in diameter, we ascribe the peak located at $1.07 \mathrm{~V}$ to oxidative removal of $\mathrm{CO}$ adsorbed on these small particles. For the medium platinum surface concentrations, in addition to the 10- to 20-nm-size particles, Pt particles with a diameter of ca. 50-120 nm were found, which we believe are responsible for the appearance of the second feature at $0.9 \mathrm{~V}$ vs RHE. These two different $\mathrm{CO}$ oxidation peaks at different structures may also be related to bimodal distribution of Pt structures suggested in "Platinum deposition and AFM imaging" from the apparently doublepeaked structure of the Pt oxide reduction peak in the blank voltammetry. At even higher platinum coverages, the surface displays oxidation characteristics typical for polycrystalline platinum surfaces, which is in agreement with the presence of multiple platinum adlayers (see Fig. 4c). Interestingly, Friedrich et al. also obtained similar CVs for agglomerates of well-defined colloidal nanoparticles on gold. For particles with an average diameter of $3 \mathrm{~nm}$, they observed a peak at $1.0 \mathrm{~V}$ vs RHE (at coverages of $\theta_{\mathrm{Pt}}=0.05$ and $\theta_{\mathrm{Pt}}=0.24$ ). At $\theta_{\mathrm{Pt}}=0.39$, a second peak at $0.87 \mathrm{~V}$ vs RHE was observed, which, as the CV displays polycrystalline platinum characteristics, was attributed to $\mathrm{CO}$ oxidizing on the nanoparticle agglomerates. In addition, on small Pt nanoparticles with a mean particle size of $1.9 \mathrm{~nm}$ supported on GC, Maillard et al. also report a CO stripping peak at $0.99 \mathrm{~V}$.

It is noteworthy that, although our particles are much larger than those used by Friedrich et al. [9] and Maillard et al. [10-12], an effect similar to this "particle size effect" is still present. This would imply an important role of the shape or morphology (as was already implied by Friedrich et al. [9] and Arenz et al. [13]). Similar conclusions were drawn by Plyasova et al. [34, 35] in their studies on the effect of electrodeposited platinum on electrocatalytic activity. They demonstrated a significant effect of platinum electrodeposition potential on the catalytic activity and ascribed these effects to the role of grain boundaries in the electrodeposits.

\section{Cyclic voltammetry: bulk $\mathrm{CO}$ oxidation}

Bulk CO oxidation experiments were performed in a COsaturated solution (bubbling $\mathrm{CO}$ for $15 \mathrm{~min}$ through the blank electrolyte). The obtained $\mathrm{CO}$ oxidation CVs on bare polycrystalline $\mathrm{Au}$ and the $\mathrm{Pt}$-modified $\mathrm{Au}$ electrodes are presented in Fig. 8.

On polycrystalline gold, $\mathrm{CO}$ oxidizes approximately between 0.8 and $1.3 \mathrm{~V}$ vs RHE, after which, the formation of gold oxides inhibits the reaction. Due to continuous readsorption of $\mathrm{CO}$ from the electrolyte, the oxidation features recorded on the Pt-modified electrodes are shifted towards higher potentials compared to $\mathrm{CO}$ adlayer stripping (this is expected if $\mathrm{CO}$ oxidation follows a LangmuirHinshelwood mechanism with strong adsorption of $\mathrm{CO}$ ). This positive shift is well known for Pt electrodes and can

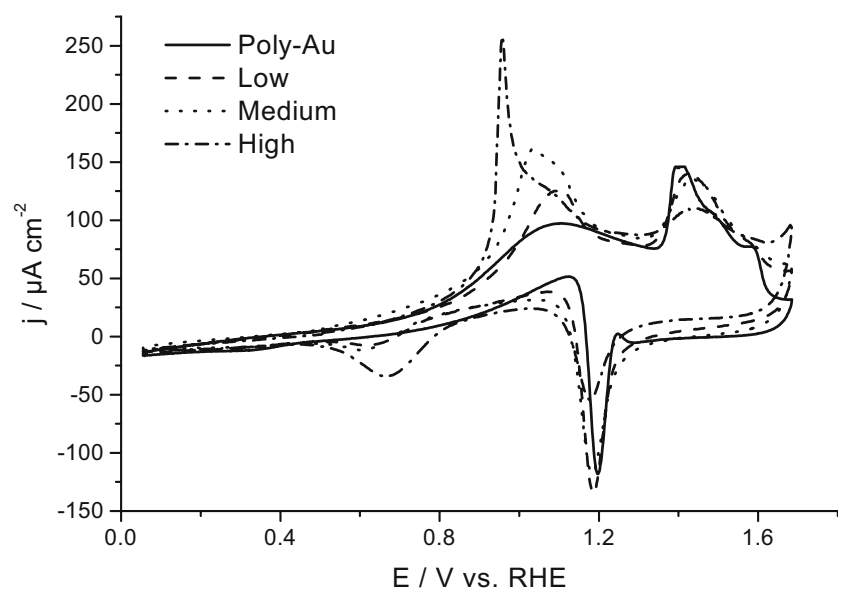

Fig. 8 Bulk $\mathrm{CO}$ oxidation voltammograms on bare gold and Ptmodified Au electrodes in $0.5-\mathrm{M} \mathrm{H}_{2} \mathrm{SO}_{4}$ at a scan rate of $20 \mathrm{mV} \cdot \mathrm{s}^{-1}$ 

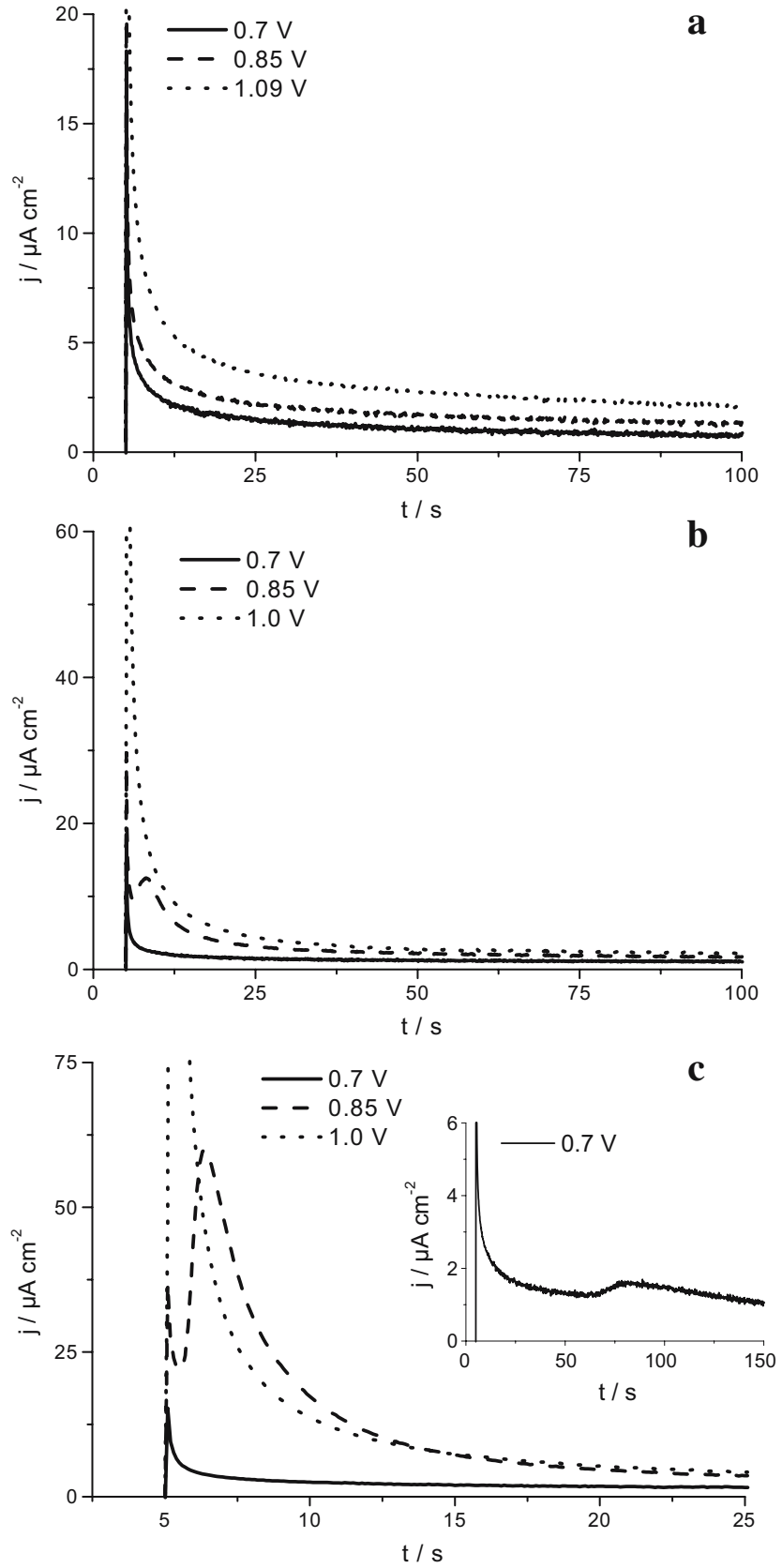

Fig. 9 Current-time transients for saturated $\mathrm{CO}$ adlayers on the three $\mathrm{Pt}-\mathrm{Au}$ electrodes with low (a), medium (b), and high platinum coverage (c). Step potentials are listed in the figure. The inset in c shows a zoom of the transient recorded at $0.7 \mathrm{~V}$ vs RHE

be as high as $300 \mathrm{mV}[32,34]$. In general, increasing the amount of Pt on the surface results in an overall increase in the current density, signifying a higher number of reactive sites. For the $\mathrm{Pt}-\mathrm{Au}$ surface with 20 - to 50 -nm-small particles, an oxidation peak is observed at $1.1 \mathrm{~V}$, which shifts to lower potentials as the particle size (and number of particles) is increased. At high Pt coverages, the main $\mathrm{CO}$ oxidation peak is located at $0.96 \mathrm{~V}$. However, even at these high coverages, the feature ascribed to oxidation on small particles is still visible at $1.1 \mathrm{~V}$.

\section{Chronoamperometry}

Potential-step experiments provided a more detailed picture of the kinetics of the $\mathrm{CO}$ oxidation reaction on the goldsupported platinum nanoparticles. The final potentials under investigation were $0.7,0.85$, and $1 \mathrm{~V}$ vs RHE. The resulting current-time curves for $\mathrm{Au}$ electrodes with low, medium, and high Pt surface concentrations are shown in Fig. 9a-c. All the transients recorded on the surface with the low platinum coverage display a current decay (see Fig. 9a), while the surfaces with medium and high $\mathrm{Pt}$ coverages show a peak in the transient recorded at $0.85 \mathrm{~V}$ (see Fig. 9b,c). For the highest amount of platinum, a current maximum was also found at $0.7 \mathrm{~V}$ vs RHE. At potentials higher than $1 \mathrm{~V}$, all three electrodes display a current decay, which seems identical for each surface. Considering the relatively high final potential applied, the formation of oxides on the nanoparticles is the most likely cause of this decay.

Potential-step experiments performed by Friedrich et al. [9] on nanoparticles of ca. $3 \mathrm{~nm}$ and agglomerates of these particles (ca. $16 \mathrm{~nm}$ in diameter) also showed a current decay on the small particles and a current maximum on the larger agglomerates. Based on these results, they concluded that the oxidation of $\mathrm{CO}$ on small particles follows an EleyRideal type mechanism, while a Langmuir-Hinshelwood type mechanism applies for the larger agglomerates. However, in contrast to these observations, Maillard et al. reported that chronoamperometric transients recorded on 1.9- to 3.1-nm-size particles do, in fact, exhibit current maxima in the potential range under investigation, indicating that a Langmuir-Hinshelwood type mechanism seems more appropriate [10-12].

From this perspective, it is puzzling that our ill-defined "small particles" (of 10-20 nm), which are even larger than the agglomerates used by Friedrich et al., display a current decrease rather than a current maximum. Perhaps the high size and shape dispersion of our particles leads to an overlap of the transient behavior of multiple morphologies, and thus, in an overall decaying transient. More research is needed to clarify these findings.

\section{Surface-enhanced Raman spectroscopy}

Figure 10 shows SER spectra of the $\mathrm{Pt}-\mathrm{Au}$ (medium coverage) electrode at different potentials in sulfuric acid saturated with CO. Two spectral regions are found to exhibit some important changes, as the potential is made more positive. One, comprising the low frequencies (Fig. 10a), shows three bands. The band centered at $380 \mathrm{~cm}^{-1}$ can be assigned to the stretching mode of $\mathrm{CO}$ adsorbed on a platinum bridge site. This mode blue shifts with potential with a Stark tuning rate of $-12 \mathrm{~cm}^{-1} \mathrm{~V}^{-1}$. 
Fig. 10 Low (a) and high frequency range (b) SER spectra obtained for a $\mathrm{Au}-\mathrm{Pt}$ (medium) electrode in $0.5-\mathrm{M} \mathrm{H}_{2} \mathrm{SO}_{4}$ at the indicated potentials
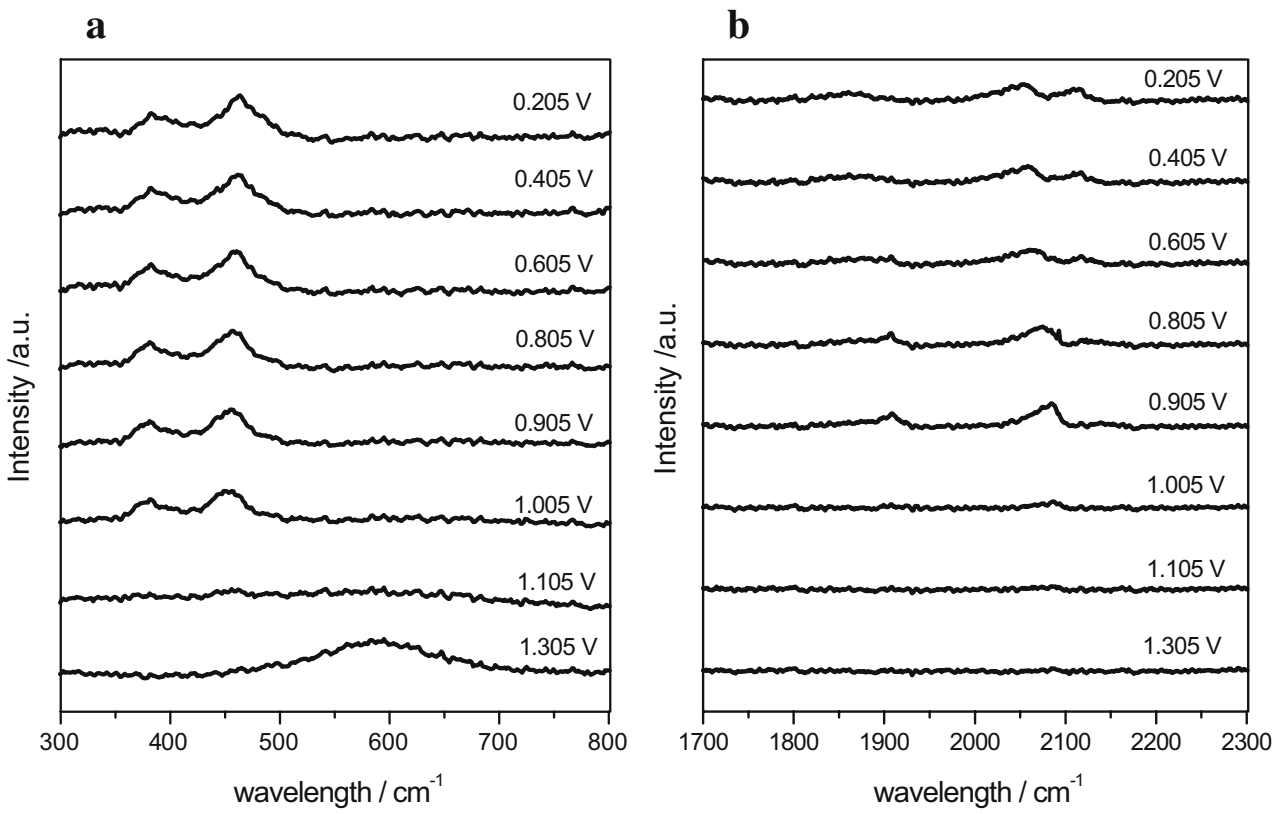

The band at $460 \mathrm{~cm}^{-1}$ corresponds to the stretch mode of CO adsorbed on platinum [36-38] and has a Stark tuning rate of $-16 \mathrm{~cm}^{-1} \mathrm{~V}^{-1}$. Both modes disappear at potentials higher than $1 \mathrm{~V}$ for medium platinum coverage. A band centered at ca. $580 \mathrm{~cm}^{-1}$ appears as the potential exceeds $1.3 \mathrm{~V}$, coinciding with the Au surface oxidation peak in the voltammogram. Weaver et al. [39, 40] attributed this band, which has a small but significant positive Stark tuning slope (ca. $10 \mathrm{~cm}^{-1} \mathrm{~V}^{-1}$ ), to the combined vibrations of $\mathrm{Au}-$ $\mathrm{O}$ and $\mathrm{Au}-\mathrm{OH}$ surface species. On the basis of other techniques, other authors have also concluded that the layer formed on gold above $1.2 \mathrm{~V}$ is composed of both surface oxide and surface hydroxide [41, 42]. Tian et al. [37] observed a band at $570 \mathrm{~cm}^{-1}$ on a pure platinum substrate and Leung and Weaver [38] a similar band on a platinum film on gold. Both attributed the band to the $\mathrm{Pt}-\mathrm{O}$ bond. Unfortunately, differentiation of these three surface species is not straightforward.

A second spectral region is defined by the 1,700 2,300 $\mathrm{cm}^{-1}$ window (Fig. 10b) and contains three peaks. The band at $1,890 \mathrm{~cm}^{-1}$, with a Stark tuning slope of $40 \mathrm{~cm}^{-1} \cdot \mathrm{V}^{-1}$, can be attributed to the CO stretching mode
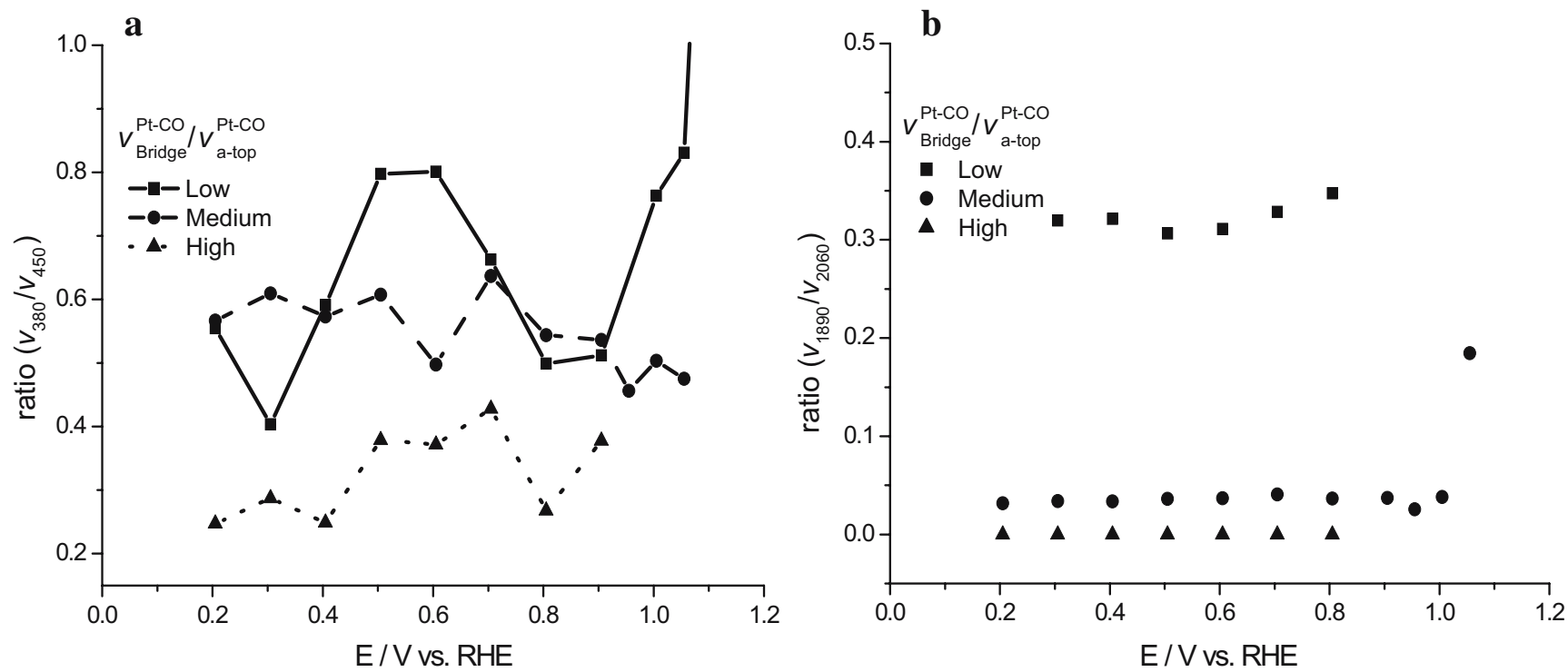

Fig. 11 Intensity ratio between the SERS intensities of bridge- and linearly bonded Pt-CO recorded on low, medium, and high platinum-covered surfaces in the low (a) and high (b) frequency range 


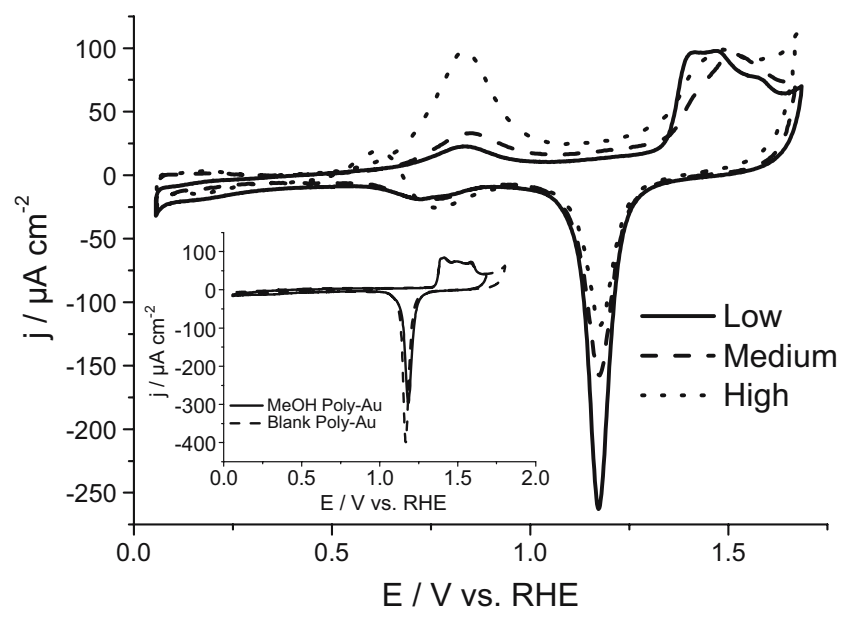

Fig. 12 Cyclic voltammograms of 0.1-M methanol oxidation on the three Pt-modified $\mathrm{Au}$ surfaces in $0.5-\mathrm{M} \mathrm{H}_{2} \mathrm{SO}_{4}$ at a scan rate of $20 \mathrm{mV} \cdot \mathrm{s}^{-1}$

on platinum bridge sites $[37,38,43]$. This band is not detectable for the gold electrode with the high platinum coverage. A second band at $2,050 \mathrm{~cm}^{-1}$ can be assigned to the top bound $\mathrm{CO}$ on platinum [36-40,43], and it shows a Stark tuning of $50 \mathrm{~cm}^{-1} \cdot \mathrm{V}^{-1}$. A third band at $2,120 \mathrm{~cm}^{-1}$ is ascribable to the stretching frequency of $\mathrm{CO}$ adsorbed atop on gold. It red shifts with an approximate Stark tuning slope of $40 \mathrm{~cm}^{-1} \cdot \mathrm{V}^{-1}[43,44]$.

The bands described above are observed for all the generated platinum-covered surfaces, and all display similar characteristics. The $\mathrm{CO}$ bands are present at potentials negative with respect to the oxidation peak in the voltammograms, and the intensities are almost constant if they involve $\mathrm{Pt}-\mathrm{CO}$ bonds. In the case of the $\mathrm{Au}-\mathrm{CO}$ mode, the band intensities are decreasing at more positive potentials, analogous to the oxidation of $\mathrm{CO}$ on pure gold electrodes [44]. The band involving $\mathrm{OH}$ species on the surface $\left(590 \mathrm{~cm}^{-1}\right.$ band) is only present at more positive potentials.

Interestingly, comparison of spectra recorded on low, medium, and high platinum-covered surfaces reveals a marked change in the ratio of the intensities of the linear and bridge bonded $\mathrm{Pt}-\mathrm{CO}$ peaks. Figure $11 \mathrm{a}, \mathrm{b}$ shows the bridge- $\left(380 \mathrm{~cm}^{-1}\right)$ vs linearly bonded $\left(450 \mathrm{~cm}^{-1}\right) \mathrm{Pt}-\mathrm{CO}$ ratios recorded on low, medium, and high platinum-covered $\mathrm{Au}$ surfaces for the low and high frequency range, respectively. The ratios shown are obtained by dividing the area of the peak ascribed to linearly bonded $\mathrm{CO}$ by the area of the peak ascribed to bridge-bonded CO. Apparently, $\mathrm{CO}$ seems to favor a bridge-bonded position on smaller particles, while the Pt-atop position is preferred for larger particles and polycrystalline platinum surfaces. Although these results are by no means conclusive, they tentatively suggest important differences in morphology for the different deposition procedures. Precise interpretation of these data is not trivial, as many unknown factors, e.g., the CO coverage, can also influence the bridge-atop ratio. Moreover, while we can ascribe a peak in the SER spectra to bridge- or linearly bonded $\mathrm{CO}$, the exact nature to the binding site is not known. Interestingly, Park et al. and Maillard et al. have observed a decrease in the contribution of bridge-bonded $\mathrm{CO}$ with particle size on carbonsupported Pt particles. This suggests a possible role of the support and the deposition procedure, or both.

Methanol and formic acid oxidation

The effect of the Pt preparation procedure was also studied for the oxidation of methanol and formic acid. The reactions were investigated using cyclic voltammetry and chronoamperometry.

\section{Cyclic voltammetry}

The CVs for the methanol and formic acid oxidation on the $\mathrm{Pt}-\mathrm{Au}$ electrodes can be found in Figs. 12 and 13, respectively. The inset in Fig. 12 demonstrates that bare gold is virtually inactive towards the oxidation of methanol. However, deposition of even a small amount of Pt on the gold substrate immediately leads to the appearance of a peak at $0.84 \mathrm{~V}$ vs RHE. As the amount of Pt is increased, the total charge of the $\mathrm{MeOH}$ oxidation peak increases, while the onset of the reaction decreases from 0.65 to $0.6 \mathrm{~V}$ and $0.55 \mathrm{~V}$ when going from low to medium and high $\mathrm{Pt}$ concentrations, respectively.

While gold is inactive towards the oxidation of methanol, it can oxidize formic acid at sufficiently high potentials, especially in the absence of strongly adsorbing anions (see Fig. 13) [45-48]. The onset of the $\mathrm{HCOOH}$ oxidation on a polished gold electrode lies at ca. $0.8 \mathrm{~V}$.

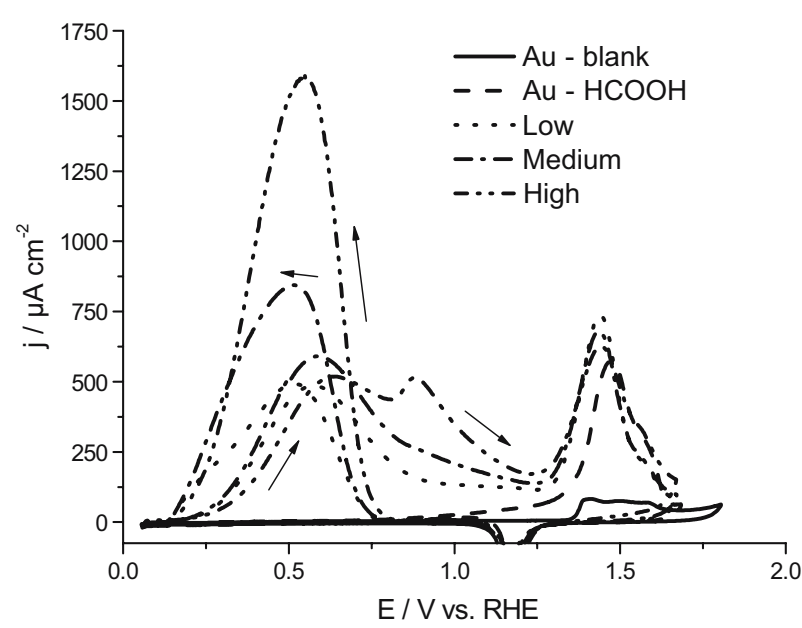

Fig. 13 Cyclic voltammograms of 0.1-M formic acid oxidation on the three Pt-modified $\mathrm{Au}$ surfaces in $0.5-\mathrm{M} \mathrm{H}_{2} \mathrm{SO}_{4}$ at a scan rate of $20 \mathrm{mV} \cdot \mathrm{s}^{-1}$ 


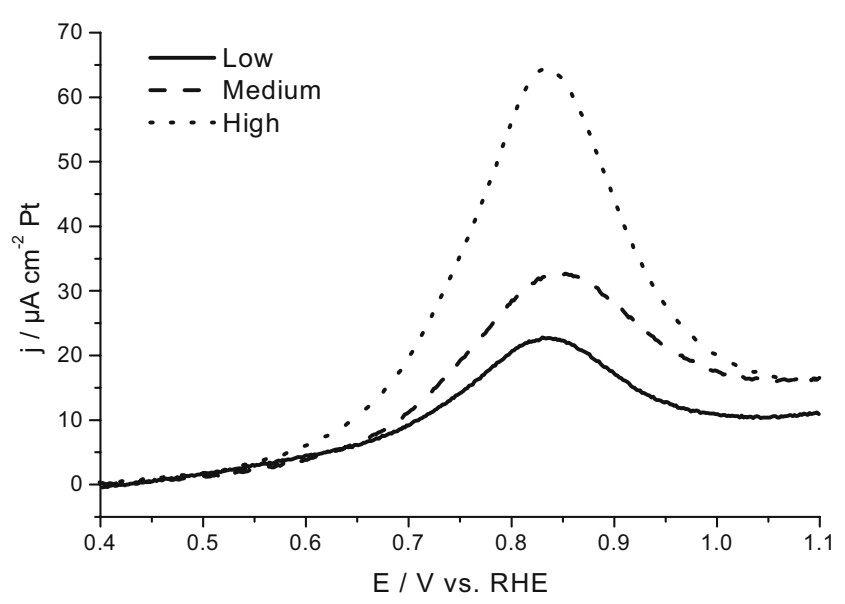

Fig. 14 Cyclic voltammograms of the methanol oxidation activity for the different $\mathrm{Pt}$ concentrations, normalized for the amount of Pt in $0.5-\mathrm{M} \mathrm{H}_{2} \mathrm{SO}_{4}$ at a scan rate of $20 \mathrm{mV} \cdot \mathrm{s}^{-1}$

Deposition of small amounts of platinum results in the appearance of an oxidation peak at $0.58 \mathrm{~V}$ vs RHE in the positive-going scan, which shifts to more positive potentials as the platinum coverage is increased. At high platinum coverages, a second feature at $0.89 \mathrm{~V}$ becomes visible. A similar feature was also observed for polycrystalline platinum electrodes [49], which leads us to conclude that this peak is most likely due to oxidation of formic acid on large particles and polycrystalline platinum overlayers. The peak at $0.58 \mathrm{~V}$ can be ascribed to the oxidation of $\mathrm{HCOOH}$ to $\mathrm{CO}_{2}$ on $\mathrm{Pt}$ sites, which are unblocked by preadsorbed poisoning species such as $\mathrm{CO}_{\text {ads }}[49,50]$. Compared to polycrystalline gold, the onset of the formic acid oxidation on Pt-modified $\mathrm{Au}$ electrodes is shifted to considerably more negative potentials (at ca. $0.2 \mathrm{~V}$ vs RHE) [49]. In the negative-going scan, the reaction proceeds on a surface that has been oxidatively stripped of preadsorbed blocking species. Therefore, higher current densities are obtained.
To compare the methanol and formic acid oxidation activities of the platinum-modified surfaces, the CVs were normalized for the surface area of platinum deposited. The amount of surface-active platinum was estimated by integration of the $\mathrm{Pt}$ oxide reduction peak and was comparable with the experiments described in previous sections. The resulting graphs are presented in Figs. 14 and 15. Although the platinum oxide reduction charge is only a rough estimate of the total platinum coverage, Fig. 14 clearly shows that larger Pt particles are more active towards the methanol oxidation than smaller particles (of equal active surface area). Apparently, the oxidation of methanol suffers from the same particle size effect as carbon monoxide. Figure 15a,b shows similarly corrected plots for the oxidation of $\mathrm{HCOOH}$ in the positive- and negative-going scan, respectively. In the positive-going scan, the current density is highest for the surface with the lowest Pt coverage. As the amount of platinum is increased, the current maximum decreases, which implies that smaller particles are more active towards formic acid oxidation than larger polycrystalline-like structures. It is also likely that surface poisoning plays an important role on the large particles. In the return scan, however, the oxidation activity increases with the amount of platinum deposited. As the potential decreases below $0.3 \mathrm{~V}$, the order of the oxidation activity is again inverted, with the low $\mathrm{Pt}-\mathrm{Au}$ surface now being more active than the higher coverages. These results suggest that larger particles are more active towards the oxidation of formic acid, but also poison faster.

Park et al. [8] explained the decreasing methanol reaction rate for a decreasing particle size by a loss of adjacent available Pt terrace sites on nanoparticles smaller than $4 \mathrm{~nm}$ in diameter. They suggested that the dissociation of methanol to reactive intermediates and chemisorbed $\mathrm{CO}$ requires an ensemble of catalytically active terrace sites.
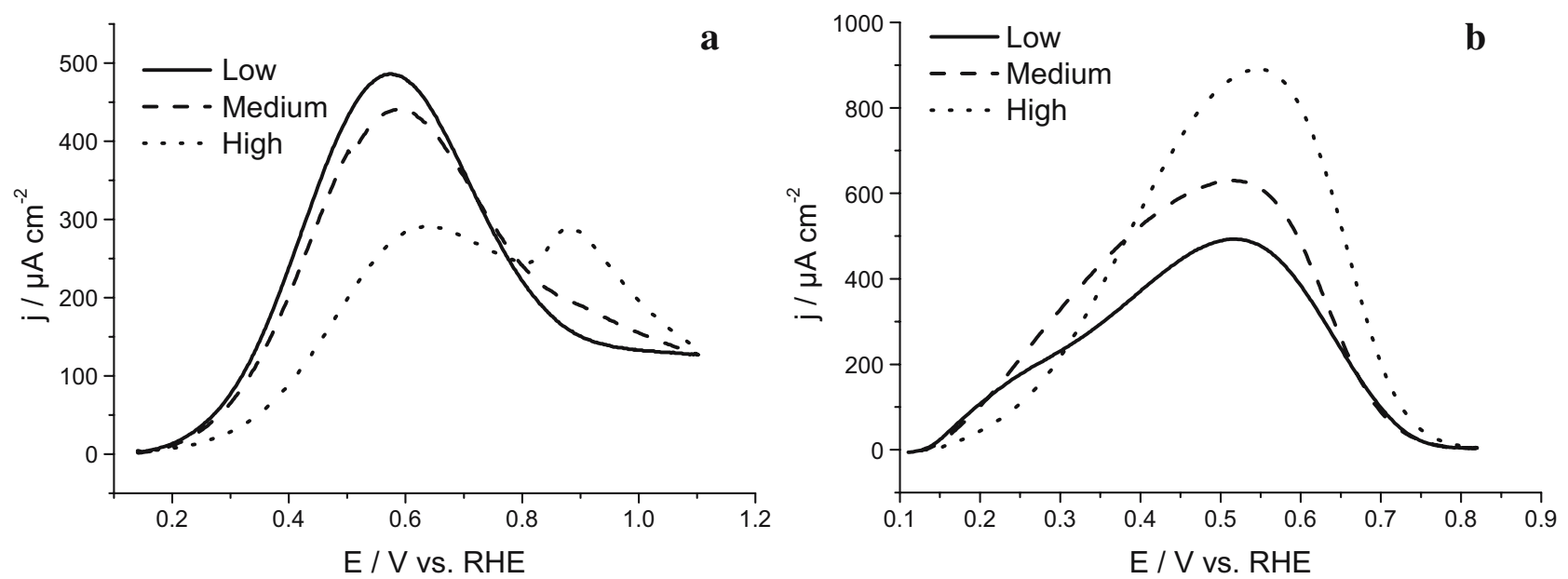

Fig. 15 Cyclic voltammograms of the formic acid oxidation activity for the different Pt concentrations, normalized for the amount of Pt, with a the positive-going scan and $\mathbf{b}$ the negative-going scan in $0.5-\mathrm{M} \mathrm{H}_{2} \mathrm{SO}_{4}$ at a scan rate of $20 \mathrm{mV} \cdot \mathrm{s}^{-1}$ 
Thus, the decreasing oxidation activity for decreasing particle size can be attributed to a drop in the number of Pt "ensemble sites" available to the adsorption and decomposition of methanol. The fact that we can still observe an effect of the particle morphology on the reaction characteristics even for particles with a diameter up to ca. $120 \mathrm{~nm}$ again suggests that the shape and morphology, rather than actual particle size, play a predominant role in the reaction kinetics.

Interestingly, from a study of the $\mathrm{MeOH}$ oxidation reaction on stepped platinum electrodes of $[n(111) \times(111)]$ orientation, Housmans et al. [51] concluded that methanol preferably decomposes on step sites rather than terrace sites. Although these findings seem to contradict those of Park et al. [8], more recent results presented by Housmans et al. show that the $\operatorname{Pt}(110)$ surface is less active towards methanol oxidation than the stepped surfaces $\mathrm{Pt}(554)$ and $\mathrm{Pt}$ (553) (of $[(n-1)(111) \times(110)]$ orientation) [52]. Based on these results, it was suggested that sites with both a step and terrace site may be particularly favorable "ensemble sites" for dissociative adsorption of methanol. As formic acid does not need these "ensemble sites," the oxidation activity increases with decreasing particle size.

\section{Conclusion}

The electrooxidation characteristics of carbon monoxide, methanol, and formic acid on Pt particles of varying size were investigated by voltammetry and chronoamperometry. The particles were generated by galvanostatic deposition of platinum on polished polycrystalline gold electrodes. Three surfaces with low, medium, and high Pt coverages were generated by galvanostatic deposition of platinum on polished polycrystalline gold electrodes and characterized by voltammetry and AFM. The electrodes with low and medium platinum coverages consisted of small ill-defined particles with diameters ranging from 10 to 20 and 10 to $120 \mathrm{~nm}$, respectively. At higher platinum coverages, polycrystalline Pt overlayers are formed. Although it should be kept in mind that Pt interacts strongly with $\mathrm{Au}$ and may form alloys, the voltammetric results obtained are in sufficiently good agreement with previous results that the role of the support is secondary to obtained particle morphology.

Based on CO stripping voltammetry and bulk $\mathrm{CO}$ oxidation experiments, we conclude the following:

1. $\mathrm{CO}$ stripping and bulk $\mathrm{CO}$ oxidation experiments on irregularly shaped particles with an average diameter of 10-20 nm display a pronounced particle size effect, while Friedrich et al. [53] observe polycrystalline platinum-like oxidation characteristics for 16-nm-large agglomerates of well-ordered particles. Therefore, not the size, but the shape of the particles or morphology of the platinum seems crucial to the oxidation characteristics.

2. Current-time transients recorded on these small 10- to 20-nm-size particles showed a current decay. On larger particles, a peaked response was obtained, clearly suggesting a Langmuir-Hinshelwood type mechanism.

3. SERS experiments indicated a difference in the ratio between $\mathrm{CO}$ bonded linearly and in bridge configuration on the small, medium, and large Pt nanoparticles, suggesting important dissimilarities in surface morphology for the different deposition procedures.

4. The oxidation activity of methanol was found to decrease with the particle size, as was also observed for the $\mathrm{CO}$ oxidation, while the formic acid oxidation rate increases with particle size. Again, a "particle size effect" is observed for nanoparticles of ca. $120 \mathrm{~nm}$ in diameter, which is much larger than the particles for which a particle size effect has been reported in the literature. The foregoing implies once more that the "particle size" is not as important as the morphology.

As a final note, we believe the most striking observation reported in this paper is that the previously reported particle size effects for the oxidation of $\mathrm{CO}$, methanol, and formic acid are apparently mimicked by electrodeposited $\mathrm{Pt}$ structures and agglomerates of much larger size. This points to an important role of structure and morphology of the Pt catalyst beyond particle size. Nevertheless, any real progress in this field must come from experiments on well-defined and well-characterized catalysts.

Acknowledgment This research was supported by The Netherlands Foundation for Scientific Research (NWO).

\section{References}

1. Wilson MS, Garzon FH, Sickafus KE, Gottesfeld S (1993) J Electrochem Soc 140:2872

2. Parsons R, VanderNoot T (1988) J Electroanal Chem 257:9

3. Sattler ML, Ross PN (1986) Ultramicroscopy 20:21

4. Bregoli LJ (1978) Electrochim Acta 23:489

5. Takasu Y, Ohashi N, Zhang XG, Murakami Y, Minagawa H, Sato S, Yahikozawa K (1996) Electrochim Acta 41:2595

6. Frelink T, Visscher W, van Veen JAR (1995) J Electroanal Chem 382:65

7. Cherstiouk OV, Simonov PA, Savinova ER (2003) Electrochim Acta 48:3851

8. Park S, Xie Y, Weaver MJ (2002) Langmuir 18:5792

9. Friedrich KA, Henglein F, Stimming U, Unkauf W (2000) Electrochim Acta 45:3283

10. Maillard F, Eikerling M, Cherstiouk OV, Schreier S, Savinova E, Stimming U (2003) Faraday Discuss 125:357 
11. Maillard F, Schreier S, Hanzlik M, Savinova ER, Weinkauf S, Stimming U (2005) Phys Chem Chem Phys 7:385

12. Maillard F, Savinova ER, Stimming U (2007) J Electroanal Chem 599:221

13. Arenz M, Mayrhofer KJJ, Stamenkovic V, Blizanac BB, Tomoyuki T, Ross PN, Markovic NM (2005) J Am Chem Soc 127:6819

14. Markovic NM, Ross PN (2002) Surf Sci Rep 45:117

15. Iwasita T (2002) Electrochim Acta 47:3663

16. Hamnett A (1999) Comprehensive chemical kinetics, Vol. 38, Eds. R. G. Compton, G. Hancock. Elsevier p. 635

17. Jarvi TD, Sriramulu S, Stuve EM (1997) J Phys Chem B 101:3649

18. Shibata M, Motoo S (1986) J Electroanal Chem 209:151

19. Wang H, Wingender C, Baltruschat H, Lopez M, Reetz MT (2001) J Electroanal Chem 509:163

20. Wang H, Loffler T, Baltruschat H (2001) J Appl Electrochem 31:759

21. Ota K-I, Nakagawa Y, Takahashi M (1984) J Electroanal Chem 179:179

22. Gao P, Gosztola D, Leung LWH, Weaver MJ (1987) J Electroanal Chem 233:211

23. Möller H, Pistorius PC (2004) J Electroanal Chem 570:243

24. Angerstein-Kozlowska H, Conway BE, Hamelin A, Stoicoviciu L (1986) Electrochim Acta 31:1051

25. Angerstein-Kozlowska H, Conway BE, Hamelin A, Stoicoviciu L (1987) J Electroanal Chem Inter Electrochem 228:429

26. Heyd DV, Harrington DA (1992) J Electroanal Chem 335:19

27. Bauer E (1958) Z Krist 110:395

28. Bauer E, Van der Merwe JH (1986) Phys Rev B 33:3657

29. Zangwill A (1988) Physics at surfaces. Cambridge Univ. Press, Cambridge

30. Pedersen MO, Helveg S, Ruban A, Stensgaard I, Laegsgaard E, Norskov JK, Besenbacher F (1999) Surf Sci 426:395

31. Lebedeva NP, Koper MTM, Feliu JM, van Santen RA (2000) Electrochem Commun 2:487
32. Lebedeva NP, Koper MTM, Herrero E, Feliu JM, van Santen RA (2000) J Electroanal Chem 487:37

33. Lebedeva NP, Koper MTM, Feliu JM, van Santen RA (2002) J Phys Chem 106:12938

34. Plyasova LM, Molina IY, Gavrilov AN, Cherepanova SV, Cherstiouk OV, Rudina NA, Savinova ER, Tsirlina GA (2006) Electrochim Acta 51:4477

35. Cherstiouk OV, Gavrilov AN, Plyasova LM, Molina IY, Tsirlina GA, Savinova ER (2007) J Solid-State Electrochem (in this issue)

36. Gland JL, Kollin EB (1985) Surf Sci 151:260

37. Tian ZQ, Ren B, Mao BW (1997) J Phys Chem B 101:1338

38. Leung LWH, Weaver MJ (1987) J Am Chem Soc 109:5113

39. Desilvestro J, Weaver MJ (1986) J Electroanal Chem Interfacial Electrochem 209:377

40. Zhang Y, Gao X, Weaver MJ (1993) J Phys Chem 97:8656

41. Tremiliosi-Filho G, Dall'Antonia LH, Jerkiewicz G (1997) J Electroanal Chem 422:149

42. Xia SJ, Birss VI (2001) J Electroanal Chem 500:562

43. Zou S, Williams CT, Chen EKY, Weaver MJ (1998) J Am Chem Soc 120:3811

44. Beltramo GL, Shubina TE, Koper MTM (2005) Chem Phys Chem 6:2597

45. Crepy G, Lamy C, Maximovitch S (1974) J Electroanal Chem 54:161

46. Hamelin A, Ho Y, Chang SC, Gao X, Weaver MJ (1992) Langmuir 8:975

47. Zhang Y, Weaver MJ (1993) Langmuir 9:1397

48. Chen S-L, Wu B-L, Cha C-S (1997) J Electroanal Chem 431:243

49. Lu G-Q, Crown A, Wieckowski A (1999) J Phys Chem B 103:9700

50. Capon A, Parsons R (1973) J Electroanal Chem 44:239

51. Housmans THM, Koper MTM (2003) J Phys Chem B 107:8557

52. Housmans THM, Wonders AH, Koper MTM (2006) J Phys Chem B 110:10021

53. Friedrich KA, Henglein F, Stimming U, Unkauf W (1998) Colloids Surf A Physicochem Eng Asp 134:193 